\title{
CORRESPONDENCE.
}

\section{RELATIVITY AND THE DURATION OF LIFE.}

To the Editors of the Journal of the Institute of Acturas.

SIRs,-In "Relativity and the Universe" (p. 84), Dr. H. Schmidt quotes from Hermann Weyl the following illustration of the effect of the Special Theory of Relativity on time :

"The life process of a human being may well be compared " with the movement of a clock. Its course, therefore, will " depend on the state of motion of the system of co-ordinates in 
"which the particular man is spending his life. Now imagine

"twin brothers who one day take leave of each other. Let one

" of them stay at home, i.e., let him be permanently at rest in a

"suitable system of co-ordinates. But the other is to go on a

"journey and to travel with velocities as great as possible

"relatively to his home. If, many years afterwards, this

"traveller returned home he would find himself noticeably

"younger than his brother who remained at home."

At first sight this suggests several interesting possibilities, Perhaps part of the general improvement in vitality which has oceurred in the last century may be due to the greater relative velocities of the people with regard to each other owing to the increased rapidity of locomotion ; and perhaps we ought to give better terms of life assurance to those who travel more than the average, especially to aviators who travel so much more quickly than other people.

On second thoughts, however, it would appear that if the person travelling lengthens his own life he also at the same time lengthens the lives of others pro tanto. For, according to the Theory of Relativity the effect produced is exactly the same in each system of reference relatively to the other, so that, if for example, the time of the brother who was travelling, whom we will eall A, was altered relatively to the one who stopped at home, whom we will call B, in accordance with the lorentz transformation from time $t$ to $t / \sqrt{1-v^{2} / e^{2}}=t^{1},{ }^{*}$ so also B's time would be altered in exactly the same way from the point of view of $A$. B would therefore share the advantage of $A$ 's travelling by a lengthened life in the eyes of $A$ and each would find his brother younger than himself. If it is satisfactory to us to know that to someone else we may appear younger than we consider ourselves to be and are unable to go travelling ourselves, we can console ourselves with the reflection that this effect can equally be brought about by the travels of other people and so bid them "Godspeed and a greater velocity."

It would appear necessary, however, that the traveller should never come to rest, relatively to our system of co-ordinates. If $\mathbf{A}$ returns home, unless he pays only a flying visit without stopping, he comes to rest relatively to $\mathrm{B}, v$ becomes 0 and $t^{1}$ becomes equal to $t$, so that the effect disappears. Both will, of course, have reached the same point of space-time, and so long as they remain together their times will agree, so that, considered as clocks, they will show the same reading. But for the lengthening of their lives to be permanent, the slowing down of their time which occurred while A was travelling must be cumulative and permanent. Can this be the case, considering that if a third traveller $\mathrm{C}$ left at the same time as $\mathrm{A}$ and returned at the same time as $A$ but travelled while away with different velocities from $A$, his time on his return must agree with both A's and B's time, yet his travels would have brought about a

* $v$ is the relocity of the two systems relative to each other and $c$ the veloeity of light. 
different lengthening of past time for himself and $B$ from that produced for $A$ and $B$ by $A$ 's travels?

The effect suggested, therefore, does not seem to be validly deduced from the Theory of Relativity, apart from the fact that it is deduced from the Special Theory, which does not hold in a gravitational field, and would therefore require modification in accordance with the General Theory.

In any case, A would have to travel with remarkable velocities in order to produce any "noticeable" alteration in his length of life, since even if he travelled continuously at $100 \mathrm{kms}$. per hour all his life he would prolong his life as measured by B's time by less than a second. As actuarial science has not yet reached the stage where such minute effects need be taken into accuunt the validity of the illustration is not perhaps a matter of urgent importance.

\section{I am, Sirs,}

Your obedient Servant,

6, Woodville Road,

R. D. ANDERSON.

Blackheath, S.E.

24. January 1923. 